\title{
Optimization of Small Pb-Bi Cooled Modified CANDLE Burnup based Long Life Fast Reactors
}

\author{
Zaki Su'ud', Nur Asiah A., Rida Siti NM and H. Sekimoto² \\ ${ }^{1}$ Nuclear Physics and Biophysics Research Division \\ Physics Study Program \\ Faculty of Mathematics and Natural Sciences, Institut Teknologi Bandung \\ Jalan Ganesa 10, Bandung 40132, Indonesia \\ ${ }^{2}$ Research Lab. For Nuclear Reactors, Tokyo Inst. Of Technology, O-okayama, Meguro-ku, Tokyo 152, Japan,
}

Received: 16 February 2012, Revised: 1 June 2012, Accepted: 21 June 2012

\begin{abstract}
In this study optimization of modified CANDLE burnup scheme based long life Pb-Bi Cooled Fast Reactors with natural Uranium as Fuel Cycle Input for small long life reactors has been performed. In this design the reactor cores are subdivided into several parts with the same volume in the axial directions. The natural uranium is initially put in region 1 , after one cycle of 10 years of burn-up it is shifted to region 2 and the region 1 is filled by fresh natural uranium fuel. This concept is basically applied to all regions, i.e. shifted the core of I'th region into I+1 region after the end of 10 years burn-up cycle. In this paper we discuss the characteristics of several designs of small long life $\mathrm{Pb}-\mathrm{Bi}$ cooled fast reactors with modified CANDLE burn-up scheme. Four power levels of $250 \mathrm{MWt}, 400 \mathrm{MWt}$, 600MWt, and $800 \mathrm{MWt}$ were investigated. For $250 \mathrm{MWt}$ and $400 \mathrm{MWt}$ cores we employed $67.5 \%$ high fuel volume fraction nitride fuels with large pin diameter of $1.35 \mathrm{~cm}$ while for 600 and $800 \mathrm{MWt}$ cores we employed $60 \%$ fuel volume fraction nitride fuel with $1.2 \mathrm{~cm}$ pin diameter. The results show that all cores show similar trend in k-eff pattern change, k-inf pattern change, conversion ratio pattern change, and U-238 and Pu-239 atomic density pattern changes. Maximum discharged burn-up is in the range of $26-33 \% \mathrm{HM}$, while peak power density is in the range of $340-410 \mathrm{~W} / \mathrm{cc}$.
\end{abstract}

Keywords: Modified CANDLE burn-up, Pb-Bi coolant, natural uranium, fuel cycle input, burn-up cycle, burn-up region, burn-up history

\section{INTRODUCTION}

Small long-life modular $\mathrm{Pb}-\mathrm{Bi}$ cooled fast reactors are very prospective for remote area with small-medium power consumption level. They also very good to be combined so that large turbine can be used and produces very competitive nuclear energy. (Su'ud and Sekimoto, 1995; Su'ud, 1998, Su'ud et al., 2005; Su'ud, 2008)

Modified CANDLE burn-up scheme (Su'ud and Sekimoto, 2008 and 2010) is an alternative strategy to optimally utilize natural uranium resources without the necessity of nuclear fuel enrichment and nuclear fuel reprocessing plants which are two very sensitive issues related to the nuclear non-proliferation in the world especially when it is carried out in the developing countries.

\footnotetext{
* Corresponding author.

E-mail address: szaki@fi.itb.ac.id
}

In this study, conceptual design study of small long life $\mathrm{Pb}-\mathrm{Bi}$ cooled fast reactors which can be continuously operated by only supplying natural uranium without fuel enrichment plant or fuel reprocessing plant has been performed. The optimization processes include adjustment of fuel region movement scheme, volume fraction adjustment, core dimension, etc.

\section{DESIGN CONCEPT}

In this study CANDLE (Sekimoto, 2001; Ohoka and Sekimoto, 2003 and 2004) burn-up strategy is slightly modified by introducing discreet regions. In this design the reactor cores are subdivided into several parts with the same volume in the axial directions. The natural uranium is initially put in region 1 , after one cycle of 10 years of burn-up it is shifted to region 2 and the region 1 is filled by fresh natural uranium fuel. This concept 
is basically applied to all regions, i.e. shifted the core of I'th region into I+1 region after the end of 10 years burn-up cycle (see figure 1) (Su'ud and Sekimoto, 2008 and 2010).

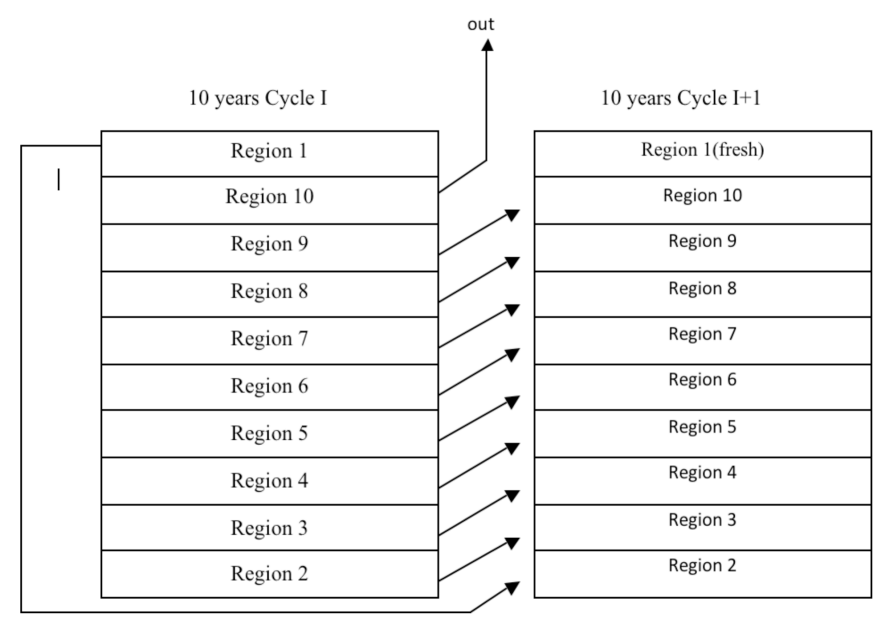

Figure 1: Burning Scheme Illustration of modified CANDLE burnup for long life $\mathrm{Pb}$-Bi cooled fast reactors which fuel cycle input is natural uranium

This type of NPP need high conversion/breeding fuel, so a high fuel volume fraction based on nitride fuel is proposed (fuel volume fraction is $60-67.5 \%$ ). The core is then optimized to fulfill the criteria that the core can maintain criticality during 10 years of burn-up using the proposed refueling scheme.

\section{CALCULATION METHOD}

The calculation is performed using SRAC code system (SRAC-CITATION system) (Okumura et al., 2002 and 2005). At the beginning we assume the power density level in each region and then we perform the burn-up calculation using the assumed data. The burn-up calculation is performed using cell burn-up in SRAC code which then give eight energy group macroscopic cross section data to be used in two dimensional R-Z geometry multi groups diffusion calculation. The average power density in each region resulted from the diffusion calculation is then brought back to SRAC code for cell burn-up calculation. This iteration is repeated until the convergence is reached.

\section{CALCULATION RESULTS AND DISCUSSION}

Table 1 shows the core main parameters of sample designs investigated in this study. Four core designs with power levels of $250 \mathrm{MWt}, 400 \mathrm{MWt}$, $600 \mathrm{MWt}$, and $800 \mathrm{MWt}$ were investigated. As mentioned in the previous session there are 10 regions in axial direction with each 10 years of fuel residence time in each regions. The fuel is of nitride type with high fuel volume fraction. The height of the active cores are $150-220 \mathrm{~cm}$, while their diameters are $155-270 \mathrm{~cm}$. Therefore the cores are in general nearly balanced cores and slightly pancake for $600 \mathrm{MWt}$ and $800 \mathrm{MWt}$ cores. The reflector width is $70 \mathrm{~cm}$ for both axial and radial directions.

Table 1: Sample Core parameters

\begin{tabular}{ll}
\hline Parameter & Value/description \\
\hline Power (MWth) & $250-800$ \\
\hline $\begin{array}{l}\text { Number of equal volume } \\
\text { region in core }\end{array}$ & 10 \\
\hline Sub cycle length (years) & 10 \\
\hline Fuel type & Nitride $(\mathrm{UN}-\mathrm{PuN})$ \\
\hline Fuel volume fraction & $60-67.5 \%$ \\
\hline Cladding volume fraction & $10-12.5 \%$ \\
\hline Coolant volume fraction & $22.5-27.5 \%$ \\
\hline Fuel diameter & $1.2-1.35 \mathrm{~cm}$ \\
\hline Coolant type & $\mathrm{Pb}-\mathrm{Bi}$ \\
\hline Axial width of each region & $15-22 \mathrm{~cm}$ \\
\hline Active core radial width & $77.5-135 \mathrm{~cm}$ \\
\hline Reflector radial width & $70 \mathrm{~cm}$ \\
\hline Reflector axial width & $70 \mathrm{~cm}$ \\
\hline
\end{tabular}

In this study we will discuss in detail about the design of $400 \mathrm{MWt}$ power level, while for other power level we will show general performance comparison as shown in Table2. Fig. 2 shows effective multiplication change during 10 years burn-up. It is shown that the effective multiplication factor changes during burn-up continuously increase. It means that in most of the regions the conversion ratio increases during 10 years of burnup process.

Table 2 Overall design comparison for various power levels

\begin{tabular}{ccccc}
\hline Power (MWt) & 250 & 400 & 600 & 800 \\
\hline $\begin{array}{c}\text { Core Radius } \\
\text { (cm) }\end{array}$ & 77.5 & 100 & 120 & 135 \\
\hline $\begin{array}{c}\text { Axial reg. } \\
\text { height(cm) }\end{array}$ & 15 & 17.5 & 20 & 22 \\
\hline $\begin{array}{c}\text { Discharge } \\
\text { Burnup(\%HM) }\end{array}$ & 32.3 & 26.7 & 31.82 & 30.47 \\
\hline $\begin{array}{c}\text { Peak Power } \\
\text { density (W/cc) }\end{array}$ & 347 & 381 & 361 & 401 \\
\hline $\begin{array}{c}\text { Initial K-eff } \\
\text { value }\end{array}$ & 1.005 & 1.002 & 1.003 & 1.002 \\
\hline $\begin{array}{c}\text { Fuel vol. } \\
\text { fraction }\end{array}$ & $67.5 \%$ & $67.5 \%$ & $60 \%$ & $60 \%$ \\
\hline
\end{tabular}




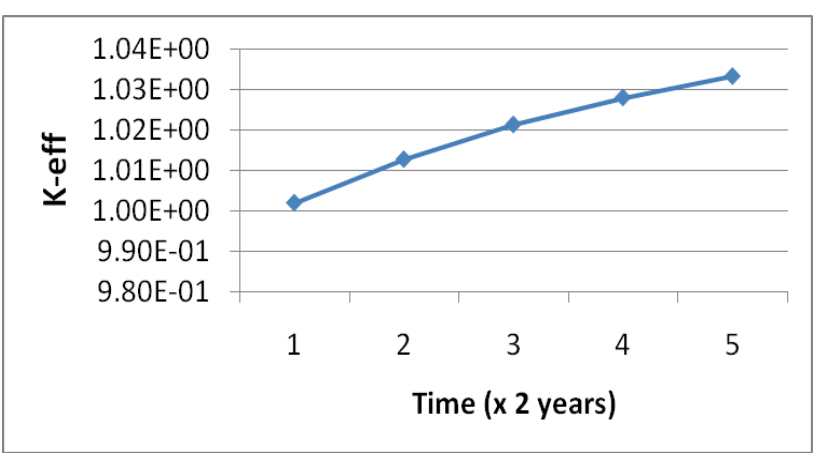

Figure 2. $\mathrm{K}_{\mathrm{eff}}$ change during burn-up process

Fig. 3 shows infinite multiplication factor change during burn-up history. It is shown that for the first 10 years of burn-up history it increases sharply due to dominant $\mathrm{U}-238$ to $\mathrm{Pu}-239$ atomic density ratio and high neutron flux value near the most active regions. During 10 to 50 years of burnup history it changes quite slowly due to relatively low neutron flux values. Then during 50-80 years of burn-up history it increase sharply and reach a peak at about 80 years of burn-up history. After 80 years of burn-up it decreases due to relatively low value of U-238 to Pu-239 atomic density ratio.

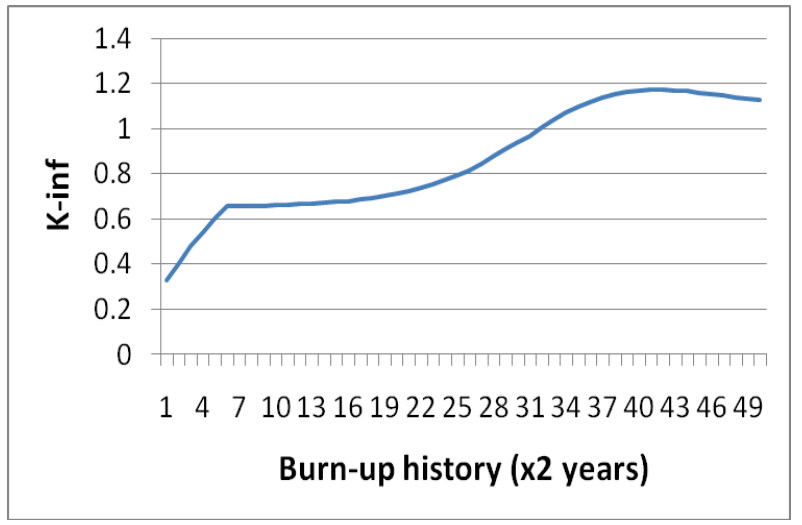

Figure 3. $\mathrm{K}_{\text {inf }}$ change during burn-up process

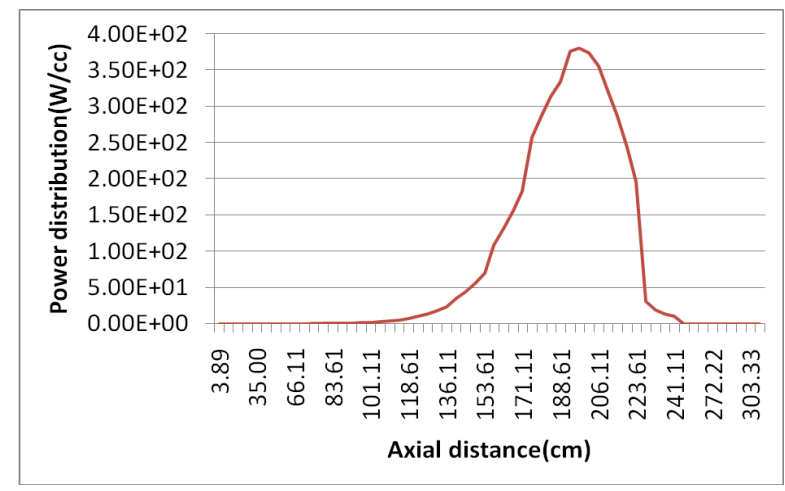

Figure 4. Axial power distribution in the center $\left(\mathrm{W} / \mathrm{m}^{3}\right)$

Fig. 4 shows axial distribution of power density. It is shown that the maximum power density is about $380 \mathrm{~W} / \mathrm{cc}$ and located at $190 \mathrm{~cm}$ of the core height (including the reflector). Such power level is still far below peak power density for conventional large fast power reactors.

Fig. 5 shows conversion ratio change during burn-up history. Its value continuously decreases during burn-up history but its slope differs from period to period. It is shown that for the first 10 years of burn-up history it decreases sharply due to significant reduction of $\mathrm{U}-238$ to $\mathrm{Pu}-239$ atomic density ratio. During 10 to 40 years of burn-up history it changes quite slowly due to relatively low neutron flux values. Then during 40-80 years of burn-up history it decreases sharply. After 80 years of burn-up it decreases but with slower rate.

Figs. 6 and 7 show the change of Pu-239 U238 atomic density change during burn-up history. U-238 atomic density value continuously decreases during burn-up history but its slope differs from period to period, while $\mathrm{Pu}-239$ atomic density value increases up to about 80 years of burn-up history then decreases. It is shown that for the first 60 years of burn-up history U-238 atomic density decreases slowly due to relatively low neutron flux values. Then during 60-90 years of burn-up history it decreases sharply. After 90 years of burn-up it still decreases significantly but the rate is slower than that of 60-90 years burn-up period.

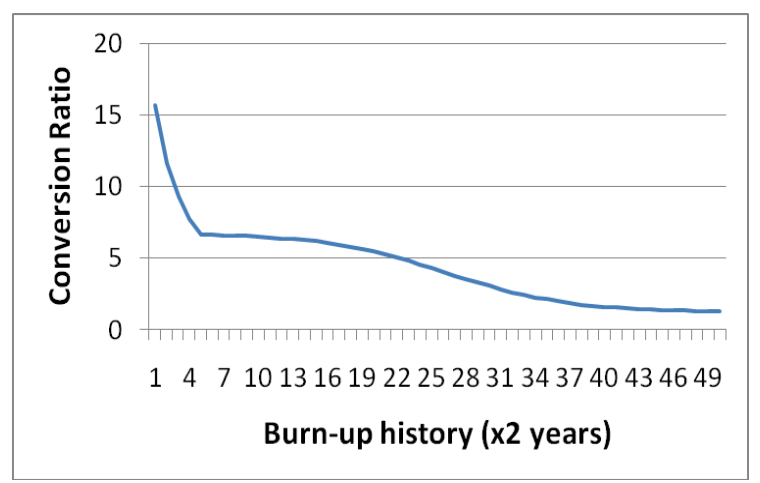

Figure 5. Conversion ratio change during burn-up history

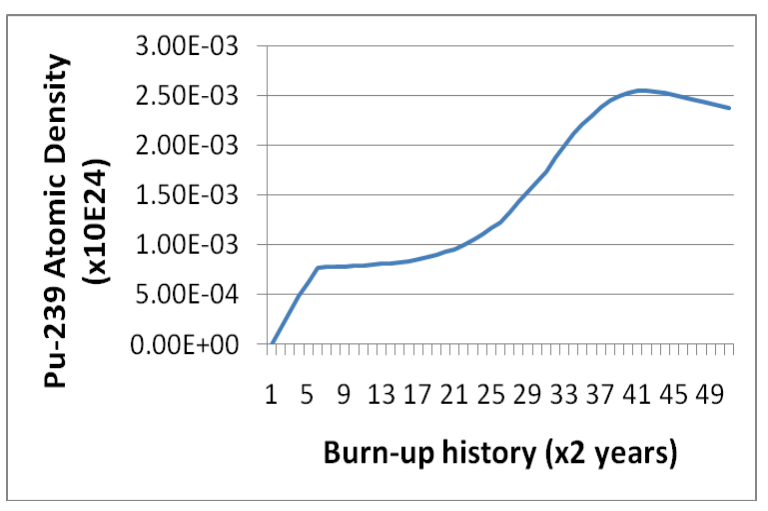

Figure 6. Pu-239 atomic density change during burn-up history 


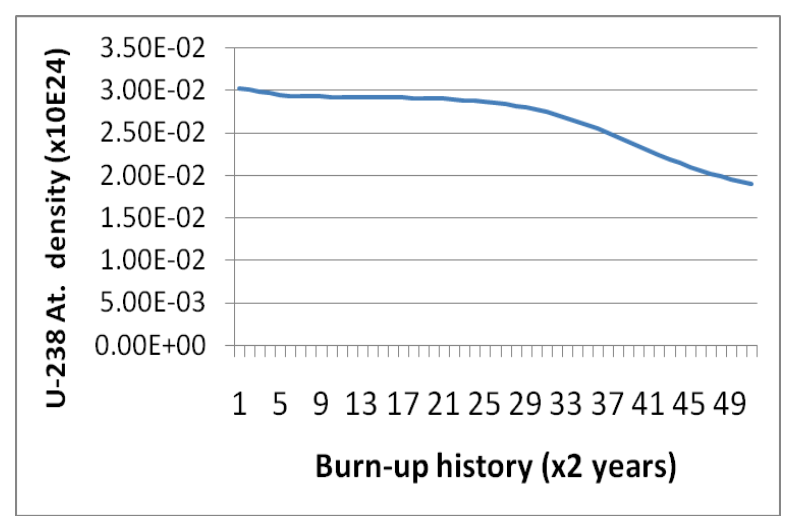

Figure 7. U-238 atomic density change during burn-up history

Fig. 6 shows that Pu-239 atomic density increases sharply during the first 10 years of burnup period due to high value of U-238 to $\mathrm{Pu}-239$ atomic density ratio and relatively high neutron flux value. On the other hands in the period of $10-50$ years of burn-up its change is relatively slow due to low neutron flux value. Then in the period of 50-80 years its value increases sharply due to in the most active regions which give high neutron flux value. Then after 80 years of burn-up history its production rate becomes slower and its value starts to decrease till the end of burn-up history.

\section{CONCLUSION}

Characteristics of several designs of small long life $\mathrm{Pb}-\mathrm{Bi}$ cooled fast reactors with modified CANDLE burn-up scheme have been discussed. Four power levels of $250 \mathrm{MWt}, 400 \mathrm{MWt}, 600 \mathrm{MWt}$, and $800 \mathrm{MWt}$ were investigated. For $250 \mathrm{MWt}$ and 400MWt cores we employed $67.5 \%$ high fuel volume fraction nitride fuels with large pin diameter of $1.35 \mathrm{~cm}$ while for 600 and $800 \mathrm{MWt}$ cores we employed $60 \%$ fuel volume fraction nitride fuel with $1.2 \mathrm{~cm}$ pin diameter. The results show that all cores show similar trend in k-eff pattern change, kinf pattern change, conversion ratio pattern change, and U-238 and Pu-239 atomic density pattern changes. Maximum discharged burn-up is in the range of $26-33 \% \mathrm{HM}$, while peak power density is in the range of $340-410 \mathrm{~W} / \mathrm{cc}$.

\section{REFERENCES}

[1] H. Sekimoto and Zaki S. (1995), Nuclear Technology, Vol. 105, no.3, p.307-313

[2] H. Sekimoto, et al (2001), Nucl. Sci. Eng., 139, p.1-12.

[3] K. Okumura et al. (2002) SRAC (Ver.2002); The comprehensive neutronics calculation code system, JAERI report.

[4] K. Okumura, K. Kaneko and K. Tsuchihashi (2005), "SRAC95; General Purpose Neutronics
Code System, “ JAERI-Data/Code 96-015, Japan Atomic Energy Research Institute, Japan.

[5] Rida S and Zaki Su'ud (2009) Int. Journal of Energy Science and Technology (IJNEST), Vol. 4 no. 3, pp. 217-222

[6] Y. Ohoka and H. Sekimoto (2003), Application of CANDLE Burnup to Block Type High Temperature Gas Cooled Reactor for Incinerating Weapon Grade Plutonium, Proc. of GENES 4/ANP 2003, Sept. 15-19, Kyoto, Japan.

[7] Y. Ohoka and H. Sekimoto (2004), Nucl. Eng. Des., 229, p.15-23.

[8] Z. Su'ud and H. Sekimoto (1995), Annals of Nuclear Energy, 22, p. 711

[9] Z. Su'ud (1998) Progress in Nuclear Energy 32 (3-4), pp. 571-577

[10] Z. Su'ud, Bakrie Arbie, and Sedyartomo S. (2005) Progress of Nuclear Energy, Vol. 47, h.212-221, 2005.

[11] Z. Su'ud and H. Sekimoto (2008)“'Optimization of Modified Candle Burn-up Scheme Based Long Life Pb-Bi Cooled Fast Reactor with Natural Uranium as Fuel Cycle Input “, PBNC 2008 Conference, Oct. 11-18, Aomori Japan

[12] Z. Su'ud (2008) Progress of Nuclear Energy, Vol. 50, p. 276-278

[13] Z. Su'ud and H Sekimoto (2010) Int. Journal of Energy Science and Technology (IJNEST), Vol 5, No. 4 , 2010, p.347-368 